\title{
Sergio Pitol, enfermo de literatura. Breve estudio sobre la "centralidad" obsesión) literaria en los ensayos de la Trilogía de la Memoria
}

\author{
Adriana Rodríguez Alfonso ${ }^{1}$
}

Resumen. El presente artículo aborda el carácter central, casi obsesivo, que tiene la literatura para el escritor mexicano Sergio Pitol en los libros de ensayos que integran su denominada Trilogía de la Memoria -El arte de la fuga (1996), El viaje (2000) y el Mago de Viena (2005)-; y el modo en el que esta "sobreabundancia" literaria deforma -por llamarlo de algún modo-, algunas de las categorías que los críticos de Pitol, con mayor o menor suerte, han empleado para definir su obra. Para ello, se han tomado tres de estos conceptos (la Autobiografía, el Viaje y la Memoria) y se ha intentado demostrar cómo ese exceso de literatura, ese empeño de Pitol por "literaturizar" cuanto encuentra a su paso, termina otorgándoles a esas categorías ciertas peculiaridades que las alejan del modo en el usualmente se han comportado en la tradición. Así, la tesis que se sostiene en este trabajo explica en parte la originalidad de la ensayística pitoliana, pues su autor consigue que estas categorías ancestrales parezcan novedosas.

Palabras clave: Sergio Pitol; ensayo mexicano y latinoamericano; literatura; autobiografía; memoria; viaje.

[en] Sergio Pitol, Sick of Literature. A Short Study about the Literary "Central Position" (or Obsession) on Trilogía de la Memoria's Essays

\begin{abstract}
The forward article is dedicated to study the central position, which could be almost obsessive, of the literature on the essay books of the "Trilogía de la Memoria" -El arte de la fuga (1996), El viaje (2000) y el Mago de Viena (2005)-, by Mexican writer Sergio Pitol. Besides, it tries to figure out the way this literary "excess" deform - just for give it a name- some of the categories that Pitol critics, with good or bad luck, have used for define the author's work. Then, among those concepts, Autobiography, Memory, Travel have been used, and also it has attended to prove how this literary "excess", this attempt of "literaturize" everything in his work, gives these categories, at the end, some characteristics that make them different from its traditional use in the literary history. So, the thesis of this article demonstrates, in some way, the originality of Pitol's essays, because he got that those old categories look innovative.
\end{abstract}

Keywords: Sergio Pitol; Mexican and Latin-American essays; literature; autobiography; memory; travel.

Sumario: 1. Introducción. 2. La "centralidad" literaria de Sergio Pitol. 3. Las intimidades del lector: una biografía simulada. 4. Memoria literaria. 5. El viaje imaginario. 6. Comentarios finales.

Cómo citar: Rodríguez Alfonso, A. (2020) Sergio Pitol, enfermo de literatura. Breve estudio sobre la "centralidad" (u obsesión) literaria en los ensayos de la Trilogía de la Memoria, en Anales de Literatua Hispanoamericana 49, 391-399.

\section{Introducción}

Sergio Pitol es uno de los autores mexicanos vivos más importantes y dentro de sus reconocimientos se incluyen el Premio Nacional de Lingüística y Literatura 1993, el Premio de Literatura Latinoamericana y del Caribe Juan Rulfo 1999 y el Premio Cervantes 2005. Aunque los estudios realizados acerca de Sergio Pitol ya son numerosos, la mayoría suele centrarse, o dedicarse por entero, a su obra ficcional. Entre ellos se encuentran La narrativa de Sergio Pitol: los cuentos (1996), de Renato Prada Oropeza; El Caldero Fáustico: la narrativa de Sergio Pitol (2006), de Laura Cázares Hernández, y Ficción, narración y polifonía: el universo narrativo de Sergio Pitol (2000), de Maricruz Castro. 
No obstante, son bien escasos los trabajos destinados por entero a su Trilogía de la Memoria (compuesto por El arte de la fuga (1996), El viaje (2000) y el Mago de Viena (2005)) y estos, además, solo suelen centrarse en el carácter híbrido de los libros que lo componen (a medio camino entre la ficción y el ensayo, en el que la crónica se combina con el relato de viajes, la autobiografía con el ensayo propiamente dicho y la crítica de arte con la narración) o, de lo contrario, en las diversas significaciones que adquiere la memoria, que por su relevancia y protagonismo en estos textos funge como uno de los centros esenciales sobre los que se articula la trilogía pitoliana.

Así, pues, resulta sorprendente que las consideraciones sobre literatura a las que, con insistencia, el autor mexicano se dedica en sus páginas hayan suscitado tan escaso examen crítico. Sergio Pitol pertenece a una escuadra cada vez más llamativa de escritores a latinoamericana que gusta de romper y rebasar los límites del ensayo académico, para fusionar la crítica con la ficción. A diferencia de otra zona de la crítica -más "correcta" y mucho menos apasionada, atorada hasta tal punto de teoría literaria que, muchas veces, la obra literaria termina siendo el material con el que ejemplifican sus teoremas, y tiene un papel secundario y ancilar ${ }^{2}$.George Orwell, en "Confessions of a Book Reviewer", los ha retratado a la perfección. -, estos "escritores-críticos", por su parte, se caracterizan por su ferviente impresionismo, por su fervor literario. En lo formal, sus textos suelen ser artefactos híbridos donde el ensayo se combina con la crónica de viajes, el cuento, la autobiografía, el diario, etc. Esa estirpe literaria, que se inicia en Montaigne y de la que Sergio Pitol es miembro indiscutible, pasa por Alfonso Reyes, y se continúa en Jorge Luis Borges, Octavio Paz, Carlos Fuentes, Juan José Saer, Ricardo Piglia y Juan Villoro. Lo que une a estos autores, además de lo dicho al principio, es la posesión de un pensamiento unitario y coherente, que hace que sus reflexiones rebasen los marcos de lo circunstancial, para adquirir continuidad y permanencia a todo lo largo de sus obras. La persistencia de ciertas ideas y obsesiones en cada uno de estos autores -y el modo armónico y orgánico en que estas aparecen- les asegura una poética propia y personal que los distingue del resto y que, a su vez, los conecta entre sí.

Todos estos escritores son lectores empedernidos y la literatura -tanto la leída, como la escrita- tiene un papel central en sus poéticas. El presente ensayo, pretende estudiar cómo funciona esta "centralidad literaria" en la obra de Sergio Pitol y demostrar el papel extremo que ella desempeña en los libros de la Trilogía de la Memoria, pues en ellos la literatura se comporta como una especie de aleph borgiano, siendo el punto en el que convergen los restantes elementos que componen la poética pitoliana. En esos ensayos, la literatura ocupa un lugar central, funcionando como una especie de hilo conductor que permea todo y da unidad a los tres libros. Allí todo es literario: un cuento de infancia se convierte en un pretexto para hablar de las primeras lecturas; un inocente encuentro entre amigos da pie a una discusión literaria o al comentario sobre un libro escrito por ellos; la visita a una ciudad es, en verdad, la descripción dada sobre ella en algún libro; una comida es el origen de una editorial; un viaje, la entrega de algún premio literario.

Los críticos de Pitol, más inteligentes en algunas ocasiones que en otras ${ }^{3}$, han sabido detectar una serie de "instancias básicas" - por llamarlas de algún modo- en la Trilogía de la Memoria: la autobiografía, la memoria y el viaje. Estas categorías atraviesan los libros, se conectan entre sí, y en buena medida son el resultado de la hibridez genérica que los caracteriza. Sin embargo, no son inalterables: es fácil imaginar que la excepcional relevancia de lo literario en los libros trae consigo algunas consecuencias. Mi tesis en este ensayo es que la literatura en la Trilogía funciona como una especie de base sobre la que la autobiografía, la memoria y el viaje se sustentan, "deformándolas", otorgándoles ciertas peculiaridades que las alejan del modo en el que tradicionalmente las conocemos. Estas diferencias les dan una apariencia especial y muchas veces sus características coinciden de tal forma que resulta difícil separarlas unas de otras. Lo importante es

${ }^{2}$ Lo que define a este grupo no es el uso de la teoría o el préstamo de recursos provenientes de otras disciplinas, sino su empleo exclusivo. Está claro que son muchos los críticos latinoamericanos que han sabido emplear estos procedimientos con pericia, combinándolos con una interpretación exhaustiva y una lectura sensible de las obras examinadas. Beatriz Sarlo, en "Los estudios culturales y la crítica literaria en la encrucijada valorativa", alerta a los críticos latinoamericanos sobre los peligros de olvidar la calidad estética a la hora de valorar una obra. El juicio artístico de un texto es lo único que verdaderamente distingue al crítico literario de un antropólogo, un historiador o un especialista de los estudios culturales; todo lo demás puede faltar. La misma Sarlo, Mabel Moraña, Néstor Canclini, Nelly Richard, entre otros, son algunos de esos críticos latinoamericanos que han sabido usar con tino la teoría literaria para sus análisis y que conformarían, si se trata de clasificar, un grupo independiente.

${ }^{3}$ La crítica sobre Pitol, como la de otros autores, sufre de unas cuantas deficiencias. La más importante es que muchos de sus estudiosos son también sus amigos y eso trae consigo que buena parte de ellos termine centrándose en anécdotas o experiencias personales que nada importan a la valoración literaria. Otro defecto visible es que como Pitol tiende a hablar de su escritura, la mayoría de sus críticos se limiten a repetirlo papagayísticamente, en lugar de comprobar si todo lo que el autor dice en teoría sobre su obra se cumple en la praxis. 
que esta autobiografía, memoria y viaje "deformados" adquieren, como en la pintura expresionista, un sello que les otorga originalidad, haciendo que estas categorías ancestrales parezcan novedosas. Además, permiten demostrar la importancia que la literatura tiene en la Trilogía, algo bien evidente cuando descubrimos el poder que ejerce sobre los restantes componentes de los libros.

\section{La "centralidad" literaria de Sergio Pitol}

La "obsesión" literaria es, ante todo, lo que justifica una auténtica poética, original y coherente, en la obra de Sergio Pitol y, al mismo tiempo, la que determina cuáles son las ideas que la conforman. No es casualidad que los tres ejes ${ }^{4}$ del pensamiento de Pitol sean la lectura, la escritura, y la crítica, tres expresiones insignes del ejercicio literario.

Esta incansable presencia de la literatura es, por momentos, excesiva y crispante. La mente de Pitol no solo literaturiza cuanta cosa encuentra a su paso -todo se vuelve materia de la ficción: cada anécdota, cada encuentro se hiperboliza, se exagera, se convierte en fin, tanto por el modo de narrar, como por el tratamiento de los hechos, en literatura-, sino que invierte la relación vida-literatura. En los libros del autor mexicano la vida siempre queda disminuida frente al arte, y la superioridad de este sobre la primera ni siquiera se cuestiona: no se vive simplemente para hacer literatura, ${ }^{5}$ se hace literatura para poder vivir. Él mismo ha dicho: "Aquello que da unidad a mi existencia es la literatura; todo lo vivido, pensado, añorado, imaginado está contenido en ella. Más que un espejo es una radiografía: es el sueño de lo real" (Pitol 2005: 54). ${ }^{6}$ La literatura no está aquí, como soñaba Stendhal, subordinada a la vida, no es su reflejo, tiene independencia propia y es, al contrario, lo que le da sentido a la existencia porque está por encima de ella. Si en otros autores las ideas de pensamiento literario servían, además, para dar su imagen general del mundo, en Pitol estas dos instancias se entremezclan. La visión de la realidad que arrojan sus ideas literarias es también literaria; el mundo de Pitol, tal y como nos los da a entender, está literaturizado, nada hay en él que no sea literatura. Pitol "lee el mundo como si fuera la continuación de un interminable texto" (Vila Matas: 35$)^{7}$. Su lenguaje no solo es literario en el aspecto formal, sino en su misma esencia: Pitol "habla en libro" (Vila Matas: 36$)$.

\section{Las intimidades del lector: una biografía simulada}

En la página 31 de El arte de la fuga, Pitol escribe:

Uno, me aventuro, es los libros que ha leído, la pintura que ha visto, la música escuchada y olvidada, las calles recorridas. Uno es su niñez, su familia, unos cuantos amigos, algunos amores, bastantes fastidios. Uno es una suma mermada por infinitas restas. (Pitol 2012: 31)

Reproducida a tutiplén en notas de contracubierta, sinopsis, artículos de periódico y ensayos académicos, esta frase se ha convertido en el lema de Pitol. El fragmento, que es maravilloso, ha sido usado para ilustrar el carácter autobiográfico de la Trilogía de la Memoria porque resume a la perfección la trayectoria vital de un artista: sus experiencias humanas (infancia, familia, amor, amistad, fracasos), y las estéticas. ${ }^{8}$

Para Philippe Lejeune, el pacto autobiográfico existe cuando podemos igualar la identidad del autor a la del narrador y la de este con el personaje principal $(13)^{9}$ y no hay dudas de que podemos localizar esto en los libros de Pitol. Su estructura misma lo ratifica: no solo él es el narrador, sino que los textos aparecen

\footnotetext{
${ }^{4}$ Estos tres ejes parecen ser, indiscutiblemente el centro de su poética. El Pitol traductor, el Pitol editor y el Pitol diplomático tienen un peso mucho menor en los libros, a pesar de que a esos oficios ha dedicado, en conjunto, buena parte de su vida.

${ }^{5}$ Vivir para hacer literatura consiste en emplear las experiencias vitales, tanto las ordinarias como las extraordinarias, en material para la escritura Alberto Giordano lo explica de este modo: "La escritura se vuelve el modo en que se experimenta lo íntimo de cada vivencia, la íntima distancia con uno mismo en el acto de amar, de cocinar..." [Giordano:60]

${ }^{6}$ Las cursivas son mías.

${ }^{7}$ Vila-Matas, además de ser un excelente escritor, es uno de los discípulos, junto a Juan Villoro, más reconocidos de Pitol. En más de una ocasión ha declarado la influencia del Cervantes mexicano en su escritura, así que las coincidencias entre ambos son de esperar.

${ }^{8}$ A estos dos tipos de experiencia podría agregar la del viaje que se sugiere en "las calles recorridas". Pero como en Pitol esta última está intrínsecamente ligada al devenir artístico, prefiero dejarlo así.

${ }^{9}$ He tomado la traducción que de este fragmento hace Alberto Giordano [170].
} 
meticulosamente marcados cronológicamente para confirmar que se trata de experiencias vividas. Por si fuera poco, El arte de la fuga y El mago de Viena cierran con fragmentos de diarios -la "escritura del yo" por excelencia-, mientras que El viaje es en sí mismo un diario, interrumpido por dos o tres fragmentos sobre Méyerhold, Marina Tsvetáyeva y Gógol.

Pero cuando entramos en los textos, todo parece echarse abajo. ${ }^{10}$ No hay rastro real de las "experiencias humanas". En términos claros, no hay rastro real de realidad, si queremos entender por ella lo cotidiano, lo habitual, la vida simple y ordinaria. El Pitol íntimo es inexistente en estos libros; cuando terminamos de leer, su vida continúa oculta: La infancia o es un vehículo para hablar de los primeros libros leídos o el pretexto para ficcionalizar, para literaturizar una experiencia. El último capítulo de El viaje, "Iván, niño ruso", es una narración rocambolesca de sus invenciones de niño y, al final, una excusa para justificar la afición de Pitol por el arte eslavo. Los escasos fragmentos que nos llegan de su familia son, junto a la infancia, la introducción para hablar -e incluso transcribir fragmentos- de sus primeros libros de cuentos que están muy permeados por el ambiente y las historias de sus primeros años (la añoranza de la abuela por la aristocracia perdida después de la Revolución Mexicana, las antiguas casonas señoriales, los ancestros italianos, etc.). No encuentro un pasaje en el que se hable de un amigo sin mencionar un libro, sin que se resalten sus habilidades literarias, sin que se reseñen con entusiasmo sus textos. En "Con Carlos Monsiváis, el joven" lo que lo une con el periodista mexicano parecen ser las librerías. El encuentro entre ambos se transforma en una seguidilla de títulos: Henry James, Joseph Conrad, Melville y Poe se convierten en garantía de amistad, como quien enumera sentimientos al ritmo de los libros comprados. Sus decepciones, sus supuestas "angustias" - como su estancia en Barcelona en El arte... o en China durante la Revolución Cultural, en El mago...--son, al final, pasajes cómicos en los que Pitol se pinta de bufón para más tarde reírse de sí mismo.

La única mención al amor está en la frase del principio.

Así, la autobiografía de Pitol es un simulacro. Incluso el pasaje dedicado a rememorar la muerte de su madre -el más intenso, en términos vitales- parece más un pretexto para hablar del psicoanálisis y el doctor Federico Pérez, que una confidencia dolorosa. En realidad, el tono sincero, íntimo, casi familiar en el que están escritas las páginas de la Trilogía se ampara en un procedimiento típico de la ensayística latinoamericana que Liliana Weinberg ha denominado la "buena fe". Esta definición alude a un tipo de contrato de lectura, propia del ensayo, en el que el ensayista simula que sus experiencias del mundo han sido vividas por él, de forma que lo "vivido aparece como una experiencia del autor en lugar de la repetición de la experiencia de otros" (Weinberg 2012: 26). Eso trae consigo que el ensayo pase, al mismo tiempo, por una extrema anonimia y una extrema intimidad que el lector experimenta durante la lectura. Esta ilusión de intimidad puede a veces ser más fuerte que cualquier otra forma de comunicación. ${ }^{11}$

Pero, en verdad, sí creo que podemos hablar de una autobiografía de Pitol. Solo que se trata de una autobiografía diferente, una variante que se desliga de la definición tradicional. Si todo en Pitol es literatura, pero literatura propia a fin de cuentas -ya sea leída o escrita/experimentada por él-: ¿acaso no podríamos leer la Trilogía como una crónica privada de su intimidad de lector? Pensemos por un momento en una biografía en la que no importen realmente los hechos, las fechas, las experiencias de vida, sino los libros que acompañaron esos hechos, la datación cronológica de esas lecturas, las experiencias de vida a las que ellas condujeron. No la historia de vida de un escritor, sino la de sus libros. No el recuento de los días de un hombre, sino el de un bibliófilo.

Hace unos meses, cuando leí la primera parte de los diarios de Piglia, encontré la definición perfecta para describir la naturaleza biográfica de los libros de Pitol:

Podría empezar por fin a pensar en una autobiografía. Sería una autobiografía seriada, una vida serial [...]. Había empezado por seguir una línea, reconstruir la serie de los libros, "Los libros de mi vida". Cómo he leído alguno de mis libros podría ser el título de mi autobiografía (Piglia: 1718). ${ }^{12}$

\footnotetext{
${ }^{10}$ Tampoco podemos aplicarle el concepto de autoficción a la obra de Pitol. Al menos no completamente. La definición que ofrece Hector Biaciotti de autoficción parte de que los episodios narrados tienen un carácter ficticio y esto es algo que aunque tiene importancia, no nos interesa aquí. [Bianciotti: 3]

${ }^{11}$ Kuisma Korhonen ofrece una explicación bien completa de este fenómeno en su libroTextual Friendship, The Essay as Imposible Encounter. From Plato and Montaigne to Levinas and Derrida.

12 Irónicamente, la "autobiografía" de Piglia es mucho menos "literaria" que la de Pitol. Un buen número de entradas del diario versan sobre las andadas nocturnas del autor, sus años universitarios, sus aventuras amorosas, etc.
} 
Recordemos solo el inicio de la frase archiconocida de Pitol que, para mí, es el fragmento más sincero: "Uno, me aventuro, es los libros que ha leído". Al final, si Pitol es ante todo, como declara en muchas ocasiones $^{13}$, lector y escritor, ¿porque ser otra cosa que el compendio de los libros leídos o escritos? ¿Hablar sobre ellos no es un modo, entonces, de escribir una autobiografía?

Ahora, pensemos en las peculiaridades de esa historia de vida. Hay allí una familia; lo que sucede es que estos no son la abuela exiliada, ni la madre muerta ni un par de parientes italianos: se trata, en su lugar, de una familia literaria, un compendio de ancestros sagrados que Pitol, como Borges con Kafka, los hace sus precursores, sus maestros literarios. Una y otra vez los mismos nombres de repiten hasta el cansancio: Manuel Martínez Pedroso, Alfonso Reyes, Faulkner, Onetti, Carpentier, el mismo Borges. Hay también un punto de inicio en la vida del biógrafo, un punto cero en su historia, solo que este no es el nacimiento de Pitol, sino su entrada primera a la literatura. La descripción de su descubrimiento de Borges tiene todo el aspecto de un ritual de iniciación:

Tal vez el mayor deslumbramiento en mi juventud fue el idioma de Borges [...]. El cuento de Borges era "La casa de Asterión"; lo leí con estupor, con gratitud, con infinito asombro. Al llegar a la frase final tuve la sensación de que una corriente eléctrica recorría mi sistema nervioso [...] Me quedé deslumbrado. Jamás había llegado a imaginar que el lenguaje pudiera alcanzar grados semejantes de intensidad, levedad y extrañeza (Pitol 2012: 183). ${ }^{14}$

La crónica de las lecturas de niño sería la infancia de su autobiografía. Una enfermedad -que guarda un sospechoso parecido con la convalecencia que a Borges lo hiciera escribir "El sur"- lo mantuvo en cama durante buena parte de sus primeros años: Llegó a la adolescencia con una "carga bastante insoportable de lecturas". La madurez y esplendor de Pitol sería la antología de las editoriales ideadas, los libros publicados, los textos leídos, las conversaciones intelectuales con los amigos. La vejez, el recuento escrito de todas esas vivencias -o esos libros $-{ }^{15}$, es decir: El arte de la fuga, El viaje, El mago de Viena.

La autobiografía de Pitol es una Bildungsroman en la que el aprendizaje no está dado por las experiencias vitales, sino por las literarias. ${ }^{16}$ Los hechos concretos, factuales, de esa historia son los fragmentos de sueños que se vuelven materia de escritura, las citas de cuentos leídos o escritos por él mismo, los apuntes de novelas en proceso que cierran cada libro. En esa crónica de bibliotecario no interesa el hombre, sino los libros. Pitol mismo ha resumido esto: "El nombre de aquel lector no tiene importancia, ni siquiera sus circunstancias, aunque conocer una y otras podría permitir trazar la crónica de una larga relación entre un hombre y sus libros predilectos" (Pitol 2005: 103).

\section{Memoria literaria}

\footnotetext{
13 "El lazo que conecta, el que une, para decirlo pronto, todos los momentos de mi vida ha sido la literatura" es un buen ejemplo. Hay muchos más, en el transcurso del ensayo me referiré a otros. [Pitol 2012: 142]

${ }^{14}$ Este momento se describe casi con las mismas palabras en El mago de Viena. La diferencia esencial es que en lugar de decir que fue el mayor descubrimiento de su juventud, allí declara que "fue, quizás, la más deslumbrante revelación en [su] vida de lector".

${ }^{15}$ Es notable que apenas haya en los libros referencia a los reconocimientos literarios más importantes. Pitol ya había recibido el Premio Juan Rulfo cuando escribió El viaje y El mago de Viena, y este último se publicó al mismo tiempo que recibiera el Cervantes. Estos premios serían un elemento más que sumar a su biografía literaria. Quizás se trate de una cuestión de modestia, falsa o no.

${ }^{16}$ La cita es bien explícita: "Mi aprendizaje es el resultado de una lectura inmoderada de cuentos y novelas, de mis empeños como traductor y del estudio de algunos libros sobre el aspecto de la novela". [Pitol 2012: 210.]
} 
Aunque la memoria y la autobiografía están estrechamente relacionadas, $-\mathrm{y}$ en muchos casos es difícil diferenciar una de la otra- he querido dedicarle una breve sección exclusivamente a la primera. En Tiempo y narración Paul Ricoeur afirma que:

solo cuando el presente acoge al pasado y al futuro como memoria e intención podemos decir que hay un horizonte, una dirección, algún lugar a dónde ir. La vivencia que se agota en el instante o la mera cronología no entienden de proyectos ni razones. Necesitamos tramas narrativas que anuden acontecimientos. En esta empresa [...] colaboran la historia y la ficción (67).

He traído aquí la cita porque, en primer lugar, es indudable que hablamos de un ejercicio de la memoria en los libros de la Trilogía, en el que el escritor, desde su presente, rememora su vida y planea proyectos futuros -o novelas, en este caso-. En segundo lugar, porque estas "tramas", estos elementos propios de la ficción, explican los abundantes pasajes narrativos allí y este es un elemento que la crítica de Pitol siempre saca a relucir a la hora de hablar de la hibridez genérica de la Trilogía.

En tercer lugar, la cita es importante por la variación que de esta definición misma se hace allí. La memoria de Pitol, "deformada" como la autobiografía por la literatura, responde a una lógica precisa. Que la inmersión constante en sus recuerdos sea involuntaria, accidental, no es más que otro simulacro. Pitol no cae en digresiones. Aunque lo finja, "no se deja llevar" por sus recuerdos de vida. Simula confesarse ante nosotros ${ }^{17}$, mostrar sus miedos más profundos, sus obsesiones más vergonzosas y hacerlo casi sin pretenderlo, como quien se sorprende después de haber traicionado sus propios secretos.

Pero en este caos aparente hay un orden razonado. Y este tiene como base, como impulso motriz, a la literatura. El ordenamiento consiste en la elección consciente y rigurosa de los elementos "biográficos" que él desliza en la Trilogía. El lazo con el que estos recuerdos pasados se traen al presente es siempre literario, o al menos, artístico. Jorge Volpi, en uno de los más lúcidos y sintéticos ensayos escritos sobre Pitol, habla de cómo a Pitol le hubiese parecido una "vulgaridad" relatar su existencia chata y simple en Veracruz. Este comportamiento responde a la constante inversión de la relación arte-vida y a la cual alude la cita de Volpi. Relatar así, sin más, sus recuerdos de vida, le parece a Pitol un acto ordinario. La vida solo alcanza trascendencia y valor cuando se parece, cuando imita ${ }^{18}$ a la literatura. En realidad, los nombres de los capítulos en los que Pitol divide El arte de la fuga son erróneos: en el índice del libro se lee "Memoria", "Escritura", "Lecturas" y "Final" pero todo es en realidad, escritura y lectura, o sea, literatura. De este modo Pitol recuerda "literariamente": no solo sus recuerdos están alterados siendo disparatados, excesivamente sentimentaloides o novelescos sino que es la literatura quien los trae del pasado hacia el presente. Un ejemplo genial del primer caso está En el arte de la fuga, cuando recuerda a dos jóvenes que observó desde su ventana una tarde en la que traducía unos cuentos del polaco. A partir de ese instante, Pitol comienza a imaginar, a inventar una trama para esos jóvenes que recuerda y de los que, en realidad, nunca supo nada. Al final del pasaje, el joven se ha convertido en un ingenuo estudiante de provincias seducido por una mujer adúltera cuyo esposo la espera en el cine de la esquina.

Los ejemplos del segundo caso se conectan directamente con el tema de la autobiografía. Consisten en la casi imposibilidad de Pitol de recordar mientras no exista una razón literaria: su recuerdo probablemente más ordinario, su penuria económica en Barcelona, es narrado para hablar de las traducciones inglesas que el autor hacía en aquel entonces y presentarnos a un hippy drogadicto cuyos diálogos dan un tono demencial al pasaje. Cuando habla de su infancia es, esencialmente, para poder hablar de los libros de Julio Verne y Cervantes, a quienes leyó por vez

\footnotetext{
${ }^{17}$ Esto, por supuesto, responde a la "buena fe" de Liliana Weinberg de la que he hablado cuando me refería a la autobiografía.

${ }^{18}$ Sobre este "bovarismo" de Pitol ahondaré con mayor profundidad en la sección dedicada al viaje.
} 
primera de niño. Este procedimiento se repite hasta el cansancio en cada uno de los lugares recorridos: su estancia en China viene a sus recuerdos por Gao Xinjiang, las visitas a Londres por Virginia Woolf.

Cuando el escritor mira hacia atrás y rememora sus años en Polonia, pocas son las cosas que cree tener en común con el Pitol de aquel entonces. Pero, rápidamente, conecta ese pasado con el presente: el enlace es, por supuesto, literario. "Uno de los lazos evidentes que encuentro con aquel muchacho de Varsovia", dice, "es una desmedida afición a la lectura" (Pitol 2012: 45).

\section{El viaje imaginado}

Muchas de las alteraciones del viaje coinciden también con las de la autobiografía y la memoria. Sin embargo, hay dos que le son exclusivas.

La primera y más sencilla se relaciona con la motivación. Es fácil imaginar que si la literatura era la razón que ligaba al pasado con el presente en la memoria, sean también los libros quienes sirvan de impulso para el viaje. Casi no hay que decirlo: en la Trilogía se viaja porque se lee. Ya en la tercera página de El arte... Pitol dice, como quien se quita de encima la responsabilidad: "Las lecturas de Julio Verne han alimentado en mí cierta desesperación de recorrer el mundo y perderme en él" (68). Esta relación viaje-lectura es doble: el viaje también incentiva la lectura. A menudo Pitol manifiesta una inclinación compulsiva e indetenible por leer a los escritores del lugar en el que se encuentra. Esto sorprende, particularmente, en El viaje, en el cual apenas hay referencias a escritores de otras nacionalidades no eslavas. Pitol se adentra en la Unión Soviética y sus lecturas se hacen cada vez más intrincadas. Los nombres de escritores de Giorgia, Armenia, comienzan a desfilar, y las lecturas de Pitol se hacen imparables.

En El libro de los pasajes, Walter Benjamin define las condiciones que debe poseer el "paseante", esa especie de flaneur que al transitar por la ciudad está libre de de toda presión, de todo objetivo y proyecto. El paseante se deja llevar por su memoria involuntaria, en nada se parece al turista o al cazador de souvenirs y observa el mundo con detenimiento, con sorpresa, como si lo viera por primera vez. ${ }^{19}$ Estos viajeros circulan por las ciudades con la misma parsimonia que el narrador de El paseo de Robert Walser, donde la caminata, más que un recorrido por los espacios citadinos, es un vagabundeo por la imaginación. Esa peculiar forma de viajar estimula las capacidades creativas del paseante, y allí los edificios y las arboledas, el espacio concreto, sólidamente observado, son menos importantes que el universo ficticio que el viajero, gracias al incentivo del paisaje, va construyendo en su imaginación. ${ }^{20}$

Algo similar ocurre en los "viajes" de Pitol, quien sale de paseo como para respirar el aire de otros libros. Pero la deformación más radical es la que experimentan los propios espacios visitados. Pitol padece de un bovarismo obsesivo, así que su vida, su realidad, le parece insatisfactoria frente a la literatura. Cuando llega a un nuevo lugar no describe lo que ve ni experimenta, se limita a transcribir con entusiasmo lo que otros autores han dicho sobre él. Pitol transita por las ciudades como si pasara las páginas de un libro: la realidad, en verdad, no le importa mucho. Su placer mayor está en comprobar que ese lugar parece literario. Cuando llega por primera vez a Venecia ha perdido sus espejuelos ${ }^{21}$ así que los contornos de la ciudad se desdibujan. A medida que la niebla vela más su visión, su "felicidad crece" porque ahora se parece "a las misteriosas Vedute de Venezia, coloreadas por Turner" (Pitol 2012:16). Su alegría es tal que a continuación comienza a copiar párrafos de la descripción que Berenson hace de Venecia. Más adelante, con la visión aun deformada, le parece ver, entre brumas, el palacio en el que vivió Byron, o el apartamento desde el que Henry James escribió Los papeles de Aspern. Después pasa a hablar de su regreso a México.

Nunca sabemos qué le parecieron El Gran Canal o la Plaza de San Marcos.

\footnotetext{
${ }^{19}$ Una de las premisas del "paseante" es que todo paseo es siempre el primer paseo. [ Benjamin: 2005]

${ }^{20}$ En El paseo nos confiesa el narrador:

Para mí pasear no sólo es sano y bello, sino también conveniente y útil. Un paseo me estimula profesionalmente y a la vez me da gusto y alegría en el terreno personal; me recrea y consuela y alegra, es para mí un placer y al mismo tiempo tiene la cualidad de que me excita y acicatea a seguir creando, en tanto que me ofrece como material numerosos objetos pequeños y grandes que después, en casa, elaboro con celo y diligencia. [Walser:42]

${ }^{21}$ Juan Villoro ha desarrollado una teoría muy interesante acerca de la constante pérdida de capacidades sensitivas de Pitol en sus libros. La pérdida de la visión y más adelante, la del oído, son, para Villoro, un artificio que el escritor despliega precisamente para que la realidad que tiene ante sus ojos aparezca "deformada".
} 


\section{Comentarios finales}

He intentado resumir en las páginas anteriores el papel medular, casi enfermizo, que tiene la literatura en la Trilogía de la Memoria de Pitol. Pensé en probarlo a través de estas categorías (Autobiografía, Memoria y Viaje) porque así el análisis -y la demostración de la que va acompañado- sería mucho más fácil tanto de realizar, como de comprender, puesto que, en esencia, a excepción de la hibridez genérica, son esos los aspectos que más suelen manejarse a la hora de hablar de la ensayística de Pitol. Pero también usé esas nociones porque, pese a haber sido llevadas y traídas una y otra vez por la crítica, son escasísimos los estudios que han notado que estas no funcionan del modo convencional en la Trilogía. ${ }^{22}$

No obstante, lo más importante es que estos no son los únicos efectos que la sobreabundancia literaria trae consigo. Otras modificaciones, igual de interesantes, son la indistinción que se da entre el Pitol crítico y el Pitol lector, o más bien, la inexistencia del primero. Otra cuestión es el poder referencial que poseen los libros, construyéndose a sí mismos como textos que remiten a otros textos, como una perenne invitación a la lectura tanto de los libros de Pitol como de la literatura universal

\section{Referencias bibliográficas}

Abadie, Nicolás Daniel (2013), "Sergio Pitol y el arte del regreso: técnicas narrativas en Juegos florales", Literatura mexicana, vol. $24, \mathrm{n}^{\circ} 2$.

Balza, José et al. (2000). Sergio Pitol: Los territorios del viajero. México D.F.: Era.

Beltrán, Rosa (2009), "Entrevista a Sergio Pitol", en www.rosabeltran.net.

Benjamin, Walter (2005). Libro de los Pasajes. Barcelona: Ediciones Akor.

Bianciotti, Héctor (1996), "La vida es muy mala novelista", entrevista con Claudio Zeiger, Primer Plano, noviembre, p. 3.

Domene, Pedro M. (1999), “El arte de la fuga de Sergio Pitol”, Revista de Literatura Mexicana Contemporánea, nº 10, pp. 122-124.

Choi, You-Jeong (2007), “Artes en conjunción en la obra de Sergio Pitol”, Espéculo, n. 37. Disponible en: https://webs.ucm.es/info/especulo/numero37/artessp.html

Fornet, Jorge (2014), "Un escritor cubano llamado Pitol”, Elogio de la incertidumbre. La Habana: Ediciones Unión.

García Díaz, Teresa (2002). Del Tajín a Venecia, un regreso a ninguna parte. Veracruz: Universidad Veracruzana.

García Díaz, Teresa (2006), "Vida y literatura: el continuo que une los mundos posibles", Revista de Literatura Mexicana Contemporánea, n 29, pp. 1021-1024.

García Díaz, Teresa (2007). Victorio Ferri se hizo Mago en Viena. Veracruz: Universidad Veracruzana.

Giordano, Alberto (2006). Una posibilidad de vida. Escrituras íntimas. Rosario: Beatriz Viterbo Editora.

Herralde, Jorge (2005), "Sergio Pitol, la elegancia y el disparate", Revista Minerva, Madrid, mayo, pp. 23-28.

Korhonen, Kuisma (2006). Textual Friendship, The Essay as Impossible Encounter. From Plato and Montaigne to Levinas and Derrida. New York: Humanity Books.

Laddaga, Reinaldo (2000), "Un refinamiento absurdo: Enumeraciones de Sergio Pitol", Ciberletras: Revista de Crítica Literaria y de Cultura, n. 2, pp. 23-26.

Disponible en: www.lehman.cuny.edu/ciberletras/v01n02/Laddaga.htm

Martínez, José Luis (1995). El ensayo mexicano moderno. Vol. 2. México D.F.: Fondo de Cultura Económica.

Lejeune, Philippe (1975). Le pacte autobiographique. Paris: Seuil.

Masoliver Ródenas, Juan Antonio (1998), "Sergio Pitol: el ejercicio de la libertad", Ínsula. Revista de Ciencias y Letras, $\mathrm{n}^{\mathrm{o}}$ 618-619, pp. 22-24.

Monsiváis, Carlos (2000), "Sergio Pitol: el autor y su biógrafo improbable", Letras libres, nº 14, pp. 36-38.

Pérez Esperanza, Silvia (2013), "Sergio Pitol, la libertad del que sueña, la vida del que escribe", en En-Saya: antología de ensayos universitarios. Xalapa-Enríquez: Universidad Veracruzana, p. 45-55.

Piglia, Ricardo (2015) Los diarios de Emilio Renzi. Años de formación. Barcelona: Anagrama.

Pitol, Sergio (2000). El viaje. México D. F.: Era.

Pitol, Sergio (2005). El mago de Viena. Valencia: Pre-Textos.

Pitol, Sergio (2012). El arte de la fuga. La Habana: Ed. Arte y Literatura.

Quintana, Cécile (2007), "Los círculos escriturales de Sergio Pitol”, Graffylia: Revista de la Facultad de Filosofía y Letras, $\mathrm{n}^{\mathrm{o}}$ 7, pp. 25-33.

${ }^{22}$ Los críticos más avezados han sido Volpi y Guillermo Sheridan, en lo que a biografía respecta. Juan Villoro es autor también de una teoría muy original en relación con el tema del viaje. 
Ricoeur, Paul (1996). Tiempo y narración. México D.F.: Siglo XXI.

Rodríguez, Reina María (2009), "Puesta en abismo", Casa de las Américas, vol.8, no 255, pp.138-141.

Rodríguez, Reina María (2011), "El hombre de los peces rojos”, Cuadernos Hispanoamericanos, n 728, pp. 23-29.

Serrato, José Eduardo (1994). Tiempo cerrado, tiempo abierto: Sergio Pitol ante la crítica. México D.F.: Era.

Salas-Elorza, Jesús (2006), "Semana Santa en Tepotztlan: un texto en el tintero de Sergio Pitol”, Espéculo, n 32, pp. 56-60.

Tabákova, Liliana (2006), “Geografías literarias de Sergio Pitol”, Revista Electrónica de Estudios Filológicos, n 12. Disponible en: www.um.es/tonosdigital/znum12/secciones/perfiles\%20CSergio\%20Pitol.htm

Vega Zaragoza, Guillermo (2006), "Sergio Pitol: la risa, el terror y la magia”, Revista de la Universidad de México, $\mathrm{n}^{\circ}$ 29 , pp. 57-62.

Disponible en: https://www.revistadelauniversidad.mx/articles/35f495e9-e778-41de-910a-ad6d48611815/sergiopitol-la-risa-el-terror-y-la-magia

Vila, María Del Pilar (2013), “El ensayo de Sergio Pitol, un cuaderno de bitácora”, Lit. lingüísta, nº 27, p. 83-96.

Vila Matas, Enrique (2002). El mal de Montano. Edición digital.

Vila Matas, Enrique (2006), "Sergio Pitol: la fuerza de la invención”, Revista de la Universidad de México, n 23. Disponible en: https://www.revistadelauniversidad.mx/articles/ff386dd1-a631-4750-b551-8463509bc36b/sergiopitol-la-fuerza-de-la-invencion

Villoro, Juan (2000), "Sergio Pitol. Los anteojos perdidos", Lateral, nº 63.

Walser, Robert (1997). El paseo. Madrid: Ediciones Siruela.

Weinberg, Liliana (2003). Ensayo, simbolismo y campo cultural. México D.F: Universidad Autónoma de México.

Weinberg, Liliana (2006). Situación del ensayo. México: UNAM.

Weinberg, Liliana (2012), "El ensayo y la buena fe", El ensayo hispánico: cruce de géneros, síntesis de formas. Génove: Droz.

Zavala, Oswaldo (2012), "La síntesis y su trascendencia: Sergio Pitol, la escritura autobiográfica y el fin del occidentalismo”, RILCE. Revista de filología hispánica, vol. 28, nº 1, pp. 257-272. 